\title{
Interpretación socioeconómica de la política neoliberal
}

\author{
Gerardo Olano \\ Oscar Armando Morales. V
}

\section{Introducción}

Desde la consolidación de la formación económica y social del pais como una economia agro-exportadora y un Estado Nacional con una estructura social, en cuya cúspide del poder económico y político figuraron los sectores hacendados, cafetaleros y financieros' ${ }^{\prime}$, las modificaciones en las formas económicas de producción asi como en la estructura social y las formas de ejercicio del poder político han sido muy escasas y poco profundas.

De 1927 a 1931, bajo la presidencia del Dr. Pio Romero Bosque primero y luego bajo la presidencia del Ing. Enrique Araujo, se intentó reestructurar el sistema de dominación tradicional oligárquico, ampliando el sistema de dominio político con la incorporación de lideres artesanales y sectores medios en los aparatos de Estado, a la par que se dictaban medidas carácter populista².

Sin embargo, estos intentos no tuvieron una expresión orgánica duradera en la organización social y política del pais. La crisis mundial, que

1. Cfr. Guidos Véjar, Rafael. "El Ascenso del Militarismo en El Salvador", UCA cditores, 1980, pags: 52-59.

2. Ibid, Pags: 100 y 104-109. 
se hizo manifiesta en el país con la depresión de los precios internacionales del café (1929-1944) y una visión extremadamente conservadora de una fracción oligárquica, encontraron en un régimen autoritario la forma de administración política para el pais.

El ascenso del estamento militar, a partir de 1932 , como clase política y particularmente la " promoción de los mayores" que en 1948, protagonizaron el derrocamiento del entonces presidente General Castaneda Castro, iniciaron un periodo de regímenes políticos caracterizados por un reformismo institucional ${ }^{3}$ que buscaba una diversificación económica y social, pero que no alterara las relaciones sociales fundamentales y las bases económicas y políticas del poder oligárquico.

Asi, la búsqueda de nuevos ejes de acumulación, por ejemplo la industrialización de los anos sesentas se apoyó en los excedentes generados a partir de la agro-exportación. La actividad industrial se mantuvo en auge gracias al dinamismo de la demanda extra-regional de de los productos tradicionales de exportación y del volumen del comercio intracentroamericano.

El desarrollo histórico de la formación social salvadoreña ha mostrado que los procesos de acumulación económica, reproducción social y política, han estado limitados en gran medida por las condiciones impuestas por la economia y la política internacional.

El funcionamiento de la economia nacional en base a su patrón tradicional fue excluyente para la satisfacción de las necesidades de reproducción de las mayorias sociales, gestando malestares sociales que devinieron en el surgimiento de luchas reinvidicativas, políticas y revolucionarias en la década de los anos setentas.

El crecimiento de los movimientos sociales de oposición con formas de organización contestarias al sistema político imperante, llevó a los gobiernos de esa década, al uso creciente de la coacción, suscitando respuestas de violencia organizada que fueron conduciendo a una palmaria crisis de hegemonia.

El golpe de Estado de 1979 y los esfuerzos posteriores de recomposición del bloque de poder y su respectiva clase dirigente en 1980, 1982 y 1984-1989, no fueron capaces de lograr su cometido, debido al corto alcance y superticialidad de las reformas estructurales.

Estó permitió a la fracción hegemónica que habia sido separada del control de los aparatos de Estado (Asamblea, Poder Ejecutivo y Judi-

3. Baloyra, Enrique. El Salvador en Transición. UCA Editores, 1984. Pág: 35. 
cial), conservar su dominio en el poder económico y en los aparatos ideológicos (prensa, radio, televisión, etc).

La sobredeterminación norteamericana en la formación social salvadorena, ejercida en términos de una modernización y democratización del Estado, institucionalizó la vía electoral como forma de acceso al poder y control de los aparatos de estado, en la década de los ochentas. Mientras tanto, la guerra civil del pais se habia agudizado, alcanzado momentos críticos que evidenciaban la dificultad de la dirección y subordinación política de la nación, bajo el esquema tradicional del ejercicio del poder político.

Es asi como la clase política identificada con el discurso "Neoliberal", asume el control de los aparatos de estado en 1989.

\section{Planteamientos Soclo-económlcos Generales del Plan de Gobler- no.}

El acceso al poder político del neoliberalismo, ha permitido plantear una estrategia de modificación de la política económica y de la política social, tendiente a restituir a una fracción hegemónica en la sociedad salvadorefia. Para ello se han declarado los siguientes objetivos y finalidades:

"Establecer un sistema de economia social de mercado, enmarcar el rol del Estado a una función normadora, abrir la economia al exterior y lograr las condiciones para mantener un crecimiento robusto y sostenido a través del tiempo"4

El cumplimiento de estos objetivos será posible, según el plan gubernamental, en el mediano plazo, a través de un proceso de "reorientación económica", una vez concluida la etapa de estabilización.

En cuanto" a lo social, se plantea: "Elevar la calidad de vida de la población e iniciar un proceso sostenido para la erradicación de la extrema pobreza"s

También aqui se insiste en una "reorientación de la sociedad", hacia un sistema "solidario y vigoroso", atribuible a la economia social de mercado.

De los objetivos anteriormente mencionados, consideramos que los de orden económico son los prioritarios, ya que incluso son los que han

4. MIPLAN, "Plan de Desarrollo Económico y Social, 1989-1994", pag. 1.

5. Ibid. 
tenido un mayor nivel de ejecución.

Los objetivos económicos son prioritarios porque permiten recuperar el terreno perdido y aún ganar nuevos espacios económicos que aseguren procesos de acumulación, subordinando asi a los de orden social.

A partir de los objetivos y los hechos de la política gubernamental se descubren los siguientes propósitos:

1) "Modernización del Estado" o readecuación de los aparatos de Estado, de acuerdo a sus intereses económicos, políticos y culturales con miras a remozar un nuevo bloque de poder.

2) Resolver el problema de la guerra civil como obstáculo principal para el ejercicio de su dirección hegemónica.

3) Instaurar las bases de un proyecto histórico de dominación que permita una recomposición del espacio social en orden a:

i) La expansión de su dominio económico, dentro de los márgenes posibles que permita la mayor apertura externa de la economia. ii) La generación de un sistema hegemónico con cierto apoyo en sectores medios.

iii) La " administración " de los sectores sociales en situación de pobreza.

Para todo ello es importante la creación y recreación de un discurso ideológico que muestre la necesidad de reducción del Estado, la legitimación del sistema político partidista y demás valores que den sustentación social y cultural a su proyecto histórico.

\section{Interpretación Crítica de los Objetivos Generales del Neoll- berallsmo.}

\section{Readecuación de los aparatos de Estado.}

La redefinición y limitación del Estado representa un paso crucial para la estrategia de "reorientación económica" formulada por el modelo neoliberal a mediano plazo: establecer un sistema de economia social de mercado. En el plano ideológico, el discurso neoliberal legitima esta redefinición y limitación del rol del Estado en términos de su distorsionante intervención - en la eficiente asignación de recursos atribuida al libre mercado-, la cual se manifiesta en los desequilibrios macroeconómicos y en un desaliento al accionar del sector privado, en la medida que absorbe recursos cuya utilización no refleja sus "costos de oportunidad social". 
Por ello, es imperativo minimizar el tamano y funciones del sector público mediante una "contra-reforma estructural" que no es más que el "rescate nacional" de los privilegios de los grupos tradicionales de poder. Invocando a las impecables "virtudes" de las leyes del mercado, el desarrollo económico y social vendrá por ańadidura, pues, la eficiencia y la competitividad se encargarán de una óptima asignación de recursos y de la satisfacción de las necesidades sociales. Con este velo ideológico se pretende ocultar lo que está detrás del mercado: lejos de la competencia, en el sentido "clásico", se tiene por el lado de la oferta, una estructura anti-competitiva y por el lado de la demanda, para la mayoria de salvadoreños, le está vedado su ingreso al reino de la" soberania del consumidor", dado su exiguo poder adquisitivo.

Constrenido el sector público a un papel subsidiario quedará expédito el camino de la "reorientación económica" - léase "reconcentración"-. de los recursos hacia la maximización de las ganancias. El cierre del IVU y del IRA junto con las reducciones de personal en algunas instituciones públicas y las privatizaciones en marcha y por venir, abren la brecha para la reconcentración de capital en aquellas actividades en las que se desplazará al sector público por su ineficiente gestión.

Si bien es cierto que los objetivos económicos del pensamiento neoliberal son de primera magnitud, la readecuación de los aparatos de estado tiene un denominador común que va más allá: un objetivo político de largo alcance que consiste en reducir la esfera de la organización y acción del Estado en la sociedad, es decir disminuir su peso o poder de acción sobre la sociedad.

Debilitar los aparatos de Estado tiene una importancia estratégica no sólo en el ámbito económico, sino también en el político. Los oponentes que virtualmente accedieran al control de los aparatos de Estado (en escenarios político-electorales futuros), se encontrarian frente a una "camisa de fuerza", llamada Estado con recursos muy limitados que darian como resultante una débil capacidad de incidir en la vida política, económica y social del pais.

El debilitamiento del Estado promovido por el neoliberalismo es posible porque las bases fundamentales de su poder radican en el dominio de las actividades económicas y de los aparatos o medios culturales, en los cuales desarrollan nuevos espacios de control (FIS, FUSADES, FEPADE, Consejo Nacional para la Cultura y el Arte, Instituto Libertad y Progreso, etc).

En consecuencia, el interés por el Estado, en tanto estructura, es un interés negativo, es visto como un "mal necesario" que hay que reducir 
al minimo. ${ }^{6}$

Especialmente porque la memoria política de los grupos tradicionales de poder registra en sus anales, las nacionalizaciones de empresas, expropiaciones de tierras y demás "perversas" interferencias a las "libertades económicas" individuales.

Por eso la "modernización del Estado" va significar la reducción a su mínima expresión y a su menor impacto económico y social, de alli que FUSADES, en armonia con el plan de Gobierno, exprese: "El esfuerzo por modernizar la función pública en nuestro pais debería estar inspirado por el logro de los siguientes objetivos: Reducir el espacio de acción e injerencia del aparato gubernamental en áreas económicas y sociales, actualizando el marco jurídico normativo y de administración de recursos del sector público.

- Optimizar el gasto público mediante la evaluación y reorganización de las unidades gubernamentales y la revisión y actualización de los procedimientos de selección, contratación y evaluación de personal.

- Descentralizar la función pública, estimulando la participación privada en programas de desarrollo."7

En suma, se trata de eliminar ciertas caracteristicas intervencionistas del Estado, pertiladas en el marco jurídico actual.

\section{Resolver el problema de la guerra clvil como obstáculo princlpal para el ejercicio de su hegemonía.}

Este objetivo ha tenido que incorporarse, de modo emergente, en el "inventario de propósitos" del actual régimen; las razones de su inclusión van desde la ofensiva de 1989 , hasta que a nivel internacional y especialmente, la política exterior norteamericana, se percata de la inoperancia de la guerra de baja intensidad y promueve la búsqueda de soluciones político-negociadas como condición favorable para la instauración de "democracias de baja intensidad".

Asumir este objetivo ha generado diferencias entre los sectores progresistas del actual régimen y aquellos identificados con el estilo tradicional de dominación en el pais.

La dinámica del proceso de solución política al conflicto puede describirse gráficamente como un embudo, en el que inicialmente los pun-

6. Esto no significa que no exista un interés político que busque el acceso y control del mismo.

7. Cłr. FUSADES. Boletin Económico y Social, No. 67 pags 1-2. MIPLAN. Op. Cit. pag 17. 
tos de discusión aludian a temáticas sociales y políticas ( sistema electoral, sistema judicial, Derechos Humanos, etc.), sobre las cuales se fueron dando acuerdos, hasta llegar a los puntos de mayor estrechez: Fuerza Armada, cese de fuego, etc, que han resultado más difíciles para la toma de acuerdos.

La solución del conflicto es de vital importancia para el régimen, tanto desde el punto de vista político (logro de credibilidad) como desde la perspectiva económica, ya que propiciaria un clima favorable para la inversión privada, variable clave en el actual modelo económico y social.

\section{Instaurar las bases de un proyecto histórico de dominación a que permita la recomposición del espacio social.}

\section{1) Restitución y expansión de su dominio económico}

Desde nuestra perspectiva, el acceso al control de los aparatos de Estado por parte del neoliberalismo, ha permitido reestablecer muchas de las condiciones para el desarrollo de los procesos de acumulación tradicionales.

En este sentido, la reprivatización de la comercialización de los principales productos de agro-exportación (café, caña de azúcar, etc), ha reintegrado a los grupos sociales tradicionales el control de los circuitos del comercio exterior de esos cultivos.

El saneamiento del sistema bancario y su proceso de reprivatización, a través de la venta de acciones, busca adjudicar esta actividad a los grupos tradicionales con cierta apertura a las sectores medios (empleados, pequenos inversionistas, etc), para convertirse en socios menores subordinados del gran capital financiero.

La privatización de otros rubros como el de la vivienda, la comercialización de los granos básicos, etc. y lo que recientemente se dió como noticia de "segunda fase de privatización" (seis ingenios azucareros, Zona Franca de San Bartolo, .Cemento Maya, etc) ${ }^{8}$, tienen por propósito abrir nuevos espacios para la acumulación de capital, favorables sobre todo a sectores sociales tradicionales o bien, de nuevos grupos sociales que de esta manera se integren al nuevo bloque de poder. Las medidas de privatización y reprivatización anteriormente destacadas son disposiciones que redistribuyen los recursos productivos del pais en favor de los grupos tradicionales de poder económico o bien, de nuevos grupos sociales "potencialmente incorporables" al nuevo bloque de poder.

8. La Prensa Gráfica, 14 de Noviembre de 1991, Pag.2. 
Las medidas de política económica o instrumentales como la política cambiaria, la política de tasas de interés, política fiscal, política monetaria-crediticia, politica de precios, etc. son mecanismos que buscan "prima facie" estabilizar los desequilibrios macroeconómicos, pero que en última instancia viabilizan el crecimiento y acumulación de capitales.

Dentro de esta estrategia de acumulación, se le asigna a la "reconversión industrial" un papel fundamental, bajo la orientación global de la promoción de exportaciones. El objetivo de mercado en el mediano plazo, es México y Centroamérica, a partir del acuerdo de zona de libre comercio, firmado en la Declaración de Tuxtla, en enero de 1991.

La idea básica de la reconversión es orientar la producción industrial hacia esos mercados, ya que su destino al mercado interno no ofrece condiciones para su realización; debido a la infima capacidad adquisitiva de la mayoria de salvadoreños.

Para el desarrollo de esa reconversión industrial, el neoliberalismo señala que existen los siguientes obstáculos:

a) "Una política laboral rigida", debido a la vigencia de un salario minimo que no permite la contratación de jóvenes y aprendices; la onerosa obligación jurídica que emana de las indemnización por despido y la permisividad legal de las huelgas.

b) Ciencia y tecnología no articulada a la producción industrial;

c) Administración ineficiente de empresas estatales, ejemplos: Hotel Presidente, Hotel de Montana, Cementos Maya, CORSAIN, etc;

d) Controles estatales en mercados de bienes: alimentos, hidrocarburos, cemento, cuero y calzado.

Para lo que se consideran obstáculos en la política laboral, las medidas no se han ejecutado, no obstante su formulación o prescripción, por ejemplo, se dice: "Liberar el mercado de trabajo...", "Flexibilizar (bajar) el salario minimo para los jóvenes y aprendices", disminuir el monto de las indemnizaciones por despido hasta un máximo de 5 anos y pago en base al $80 \%$ del salario básico. ${ }^{9}$

De lo anterior se deriva, que de concretarse la ilusión de la reconversión industrial en los términos que se concibe, los costos de la misma la pagarian los trabajadores, deteriorando sus niveles de vida.

9. FUSADES. Boletín Económico y Social. No. 69, Agosto de 1991, Pags: 3-4. 


\section{II) La generación de un sistema hegemónico con clerto apoyo en los sectores medios.}

El panorama que se pertila bajo este nuevo esquema de dominación consolidaria una estructura social que incorporaria a "nuevos ricos" al bloque de clases dominantes, las cuales en el mejor de los escenarios económicos representarian una minima porción de la población del país.

Las capas medias, a excepción de muy pocos casos de la "inteligencia" que han logrado articularse en el gobierno o en las fundaciones de la empresa privada, experimentarán un empobrecimiento relativo, dado por el congelamiento de los salarios y la elevación del costo de la vida.

Esto significa que hay una "promoción" de la pobreza, para algunos sectores de las capas medias (movilidad descendente) y por supuesto, una profundización de la pobreza de los trabajadores rurales y urbanos.

\section{III) "Administración" de sectores soclales en situación de pobreza.}

Dadas las limitaciones estructurales internas como los limites que impone la economia mundial, es previsible que el desempleo y subocupación aumente a la par que se profundiza la pobreza.

Desde la perspectiva oficial, se hace necesario el funcionamiento de organismos privados que de acuerdo con el Gobierno, "administren" o controlen culturalmente las situaciones sociales de pobreza.

Para este manejo político-social de la pobreza, el gobierno de ARENA, dentro del plan de desarrollo social, presenta un "conjunto de políticas compensatorias" que infructuosamente tratan de disminuir la pobreza, la inflación y el desempleo, generados por la aplicación de las medidas de ajuste estructural y de reorientación económica.

Asi mismo, se necesita de un planteamiento cultural cosmético que introyecte en la población, los valores del nacionalismo, de la eficiencia privada, el derecho a la propiedad ("El Salvador, un pais de propietarios"), etc. y el énfasis en problemas de agregados poblacionales vulnerables: el nino, la mujer, la tercera edad, etc, que constituyen problemas graves, pero no fundamentales.

Para el mediano plazo, se ha disenado una "Política Sectorial Social" que persigue como objetivo "el desarrollo sostenido de los sectores sociales tradicionales, mediante un proceso de reformas estructurales tendientes a aumentar la calidad y cobertura en la prestación de los servicios, especialmente en los niveles básicos de atención". ${ }^{10}$

10. MIPLAN. "Evolución Económica y Social" Política Económica y Social, 1991. pag. 209 
Asi el "desarrollo social" como el "desarrollo económico" hace referencia a "reformas estructurales" que aluden a la creación de un "Estado subsidiario", en el cual la satisfacción de las necesidades básicas y la erradicación de la extrema pobreza se atribuyan a la atmósfera de "cooperación social, espontánea y voluntaria" inmanente a la "ética del mercado" y del sector privado.

En estos términos, la solución de los problemas de las mayorias sociales queda reducida al "espiritu de solidaridad" y al "potencial creativo" de los hombres de negocios, para realizar "con conceptos técnicos la justicia social". En consecuencia, el mercado representa la oportunidad moral para los más pobres de convertirse en el "nuevo salvadoreno".

Pero cuando las ilusiones no se concretizan y el esperado "crecimiento robusto" languidece en la tristeza de la alegria que no vino, desencantando más a los "más pobres de los pobres", estos buscarán resolver sus problemas existenciales con aventuras riesgosas de cruzar desiertos, oceános y de trabajar de "hace lo todo" en alguna parte del mundo, a cambio de no estar en "algún lugar " de El Salvador.

\section{Conclusiones}

1. Desde 1881 hasta 1948 , El Salvador ha vivido en formas de Estado con matices de liberalismo económico, los Regímenes políticos que se instauraron de 1950 a 1989, representaron intentos frustrados de consolidar sistemas políticos escasamente participativos, en respuesta a las crisis generadas y acumuladas a partir de la consolidación del modelo agro-exportador.

2. El "intervencionismo" estatal del periodo 1950-1979, en todo caso estuvo signado por el principio de preservar la estructura económica tradicional y crear las condiciones materiales o "economias externas" para garantizar la continuidad del proceso de reproducción y acumulación de capital. Asi mismo el andamiaje institucional establecido (ISSS, IVU, ANDA, etc.), procuraba compensar -aunque de manera restringida - la carencia de servicios básicos para ciertos grupos sociales urbanos.

3. Con el golpe de Estado de 1979, se desarrolla un intervencionismo activo, en términos de reformismo en ciertos circuitos de acumulación del modelo agro-exportador tradicional. La incapacidad de este proyecto político de alterar sustancialmente las estructuras del poder tradicional, en la situación de una guerra civil, permitió la conserva- 
ción del poder económico y cultural de la fracción hegemónica.

4. La década de los noventas se inicia con la ejecución del proyecto "neoliberal-privatizador", cuya política económica y social está orientada en primer lugar, a reducir los aparatos de Estado (con ciertas excepciones: aparato militar, etc) como parte, no sólo de una estrategia económica sino también en función de una finalidad política. Esta doble intencionalidad persigue en última instancia, la recuperación de los circuitos de acumulación bloqueados en cierta medida por el reformismo de los anos ochentas. Este proceso de reacumulación de capital se apoyará en un mayor grado de apertura externa de la economia.

5. En el aspecto social, el neoliberalismo persigue consolidar una estructura de dominación basada en la restitucion del poder hegemónico de ciertas fracciones tradicionales y en la incorporación de "nuevos" socios minoritarios que aborden el tren de la reprivatización, la reconversión industrial y la promoción de exportaciones o bien, de cualquier otra actividad "productiva" indicada por las sehales del mercado.

6. La grave situación de los problemas sociales como el desempleo, pobreza, etc, queda confinada a "soluciones" que derivan del funcionamimiento mismo de la economia de mercado, y del "altruismo" que se pretende de los "racionales" hombres de negocios; que conjuntamente con instituciones "ad hoc" administren a los grupos sociales en situación de pobreza, prodigándoles bienes insuficientes y esperanzas. 